\title{
GRAMÁTICA \& ESCOLA, UMA ENTREVISTA COM JOÃO COSTA
}

\author{
Roberta Pires de Oliveira | Lattes | ropiolive@gmail.com \\ Universidade Federal do Paraná | Universidade Federal de Santa Catarina | CNPq \\ Izete Lehmkuhl Coelho | Lattes | izete.lehmkuhl.coelho@ufsc.br \\ Universidade Federal de Santa Catarina | CNPq
}

Isabel Monguilhott | Lattes | monguilhott@hotmail.com Universidade Federal de Santa Catarina

\section{Introdução}

João Miguel Marques da Costa é professor catedrático de Linguística na Faculdade de Ciências Sociais e Humanas da Universidade Nova de Lisboa. Licenciado em Linguística pela Faculdade de Letras da Universidade de Lisboa em 1994, doutorou-se, também em Linguística, na Universidade de Leiden (Holanda) em 1998. Realizou parte da sua investigação doutoral no MIT (Massachusetts Institute of Technology, Estados Unidos). Em 1998, recebeu o Prémio de Investigação da Associação Portuguesa de Linguística. Até novembro de 2015 foi Diretor da Faculdade de Ciências Sociais e Humanidades e presidente do Conselho Científico das Ciências Sociais e Humanidades. Lecionou em universidades de vários países: Brasil, Macau, Espanha e Holanda. Foi membro do Conselho Científico do Plano Nacional de Leitura, da Comissão Nacional do Instituto Internacional da Língua Portuguesa e do Conselho Consultivo do Instituto Camões. Foi presidente da Associação Europeia de Estudantes de Linguística (SOLE) e da Associação Portuguesa de Linguística. Atualmente é Secretário do Estado da Educação de Portugal.

Em uma rápida inspeção de sua obra já se observa o leque e o vigor de sua produção científica - são mais de 16 livros, 40 capítulos, vários artigos em revistas científicas de prestígio, inúmeras entrevistas e artigos de divulgação científica, entre outros. Eis alguns exemplos mais recentes das suas várias áreas de atuação: Handbook of Portuguese Linguistics; Language Acquisition and Development; Conhecimento Explícito da Língua. Guião de Implementação do Programa, do Ministério da Educação. Suas áreas de interesse incluem as diferentes questões sobre a gramática do português, em relação a parâmetros universais como a ordem das palavras através das línguas, as variedades do português, a aquisição da linguagem pelas crianças com desenvolvimento normal e com perturbações 
da linguagem, e a Linguística Educacional, que, desde sua nomeação como Secretário de Estado, ocupa lugar de destaque em sua vida profissional. Em entrevista à revista eLingUp em 2012, o professor afirma que não é possível ensinar língua no Ensino Médio e Fundamental sem ter uma base em linguística: "Seria tão absurdo como ensinar Biologia sem se saber nada desta área ou sem que houvesse esforços de atualização científica.” (COSTA, 2012, p. 8).

Neste momento em que a educação e a ciência no Brasil sofrem com políticas que parecem não compreender o lugar estratégico do conhecimento no mundo contemporâneo, momento em que os índices baixos do Relatório de Pisa só confirmam que nossos alunos têm dificuldade para resolver problemas cotidianos básicos que envolvem mecanismos de inferência, que não são leitores desenvoltos, que não estão familiarizados com o conhecimento científico, a publicação desta entrevista é absolutamente apropriada e necessária. Trata-se de assegurar o papel fundamental da Linguística na Escola e, consequentemente, de mostrar a importância da gramática na escola. Promover a reflexão sobre as línguas naturais, a partir de um ponto de vista naturalista, permite avanços em várias direções e pode ser uma maneira de alavancar os índices do Pisa e de modificar a sociedade.

\section{Entrevista}

Pires de Oliveira, Coelho e Monguilhott: Os estudos gramaticais atuais entendem gramática como a habilidade de usar adequadamente os recursos linguísticos, o que inclui entre outros a habilidade para perceber e avaliar diferentes variedades e para adquirir uma outra gramática, e, portanto, aprender a(s) norma(s) culta(s) da língua. Como o senhor entende que seja essa habilidade na sua dimensão gramatical?

João Costa: Todos somos falantes de múltiplas gramáticas ou de uma mesma gramática com variantes de registo, dialetais, situacionais. Quando falamos de variação, falamos de contexto, mas falamos sobretudo das propriedades da língua em que essa variação se manifesta. Quer descrevendo, mas sobretudo explicando as diferenças - como faz a linguística teórica - desenvolvemos um conhecimento mais profundo das diferenças entre registos.

Como linguista, interessa-me pouco se estamos perante várias gramáticas, várias línguas ou perante um conjunto de diferenças pontuais. Quando falo com uma criança de três meses, não falo como falo para um colega de trabalho. Isso não me torna necessaria- 
mente detentor de duas gramáticas ou falante de duas línguas, mas sim alguém suficientemente hábil para dominar a forma como falo e geri-la em diferentes contextos.

Como linguista, interessa-me entender a variação e quais os melhores instrumentos para uma descrição e explicação adequada.

Pires de Oliveira, Coelho e Monguilhott: Em que essa habilidade pode ajudar no ensino de uma nova norma da língua ou de uma outra gramática?

João Costa: Quando falamos de norma, estamos sempre a falar de convenção. Há nas normas cultas manifestações diferentes da variação: ou construções que já não são adquiridas espontaneamente por terem caído em desuso, ou construções que já não são adquiridas espontaneamente porque são apenas convenções, ou construções que não fazem parte do uso não formal da língua e que, por isso mesmo, requerem aprendizagem explícita. A habilidade de que falam consiste na capacidade de controlar o uso da língua para selecionar as formas mais adequadas em diferentes contextos.

Para isso, é necessário desenvolver consciência sobre a variação, refletir sobre a língua, colocar hipóteses e experimentar diferentes usos. Não vale a pena dizer: "isso está errado" ou "não se diz assim", quando estamos perante algo que todos dizemos. É melhor conduzir para uma atividade reflexiva, que nos permite observar os contextos em que uma forma ou outra é usada. Um trabalho desse tipo promove consciência linguística, que potência melhor uso e, simultaneamente, leva a um fortalecimento constante das habilidades gramaticais.

Pires de Oliveira, Coelho e Monguilhott: O senhor acredita que seja importante levar essa discussão para a escola? Por quê?

João Costa: Pelas razões enunciadas na resposta anterior. A escola é, para muitos, o único espaço de contato com o registo formal, com o registo acadêmico (que não são necessariamente coincidentes). Sabemos que o uso da língua é um forte fator de inclusão social. Uma escola democrática é a que promove mobilidade social e isso passa também pela capacidade de dominar diferentes registos da língua. Na medida em que a consciência linguística é um instrumento fundamental para que tal aconteça, obviamente que esta discussão é crítica para um bom desempenho do papel da escola. 
Pires de Oliveira, Coelho e Monguilhott: Mas há também o que sabemos hoje em dia sobre as línguas naturais. A conversa com a biologia, por exemplo, a linguagem nos animais, como a línguas surgiram na espécie humana coloca questões fascinantes que ainda não alcançaram a comunidade. Esse conhecimento sobre as línguas deveria estar na formação do cidadão?

João Costa: Eu não posso estar mais de acordo, mas hoje os países do mundo discutem um problema sério: a obesidade curricular. A quantidade de conteúdos que os alunos aprendem é imensa. E há um momento em que é preciso tomar opções sobre o tempo disponível para ensinar o que é essencial, de forma a que os alunos aprendam de facto. $\mathrm{Na}$ formação dos professores, não tenho a menor dúvida [de que esse conhecimento é necessário].

Pires de Oliveira, Coelho e Monguilhott: Em que aspectos o senhor acredita que a linguística pode contribuir para a escola?

João Costa: De múltiplas formas. A linguística oferece instrumentos para descrições mais adequadas, dá-nos pistas claras sobre o absurdo do preconceito linguístico, explica a variação. Ao sabermos mais sobre o desenvolvimento linguístico, a forma como a língua é processada sob ponto de vista psico e neurolinguístico, temos indicadores precisos sobre os conteúdos a trabalhar, mas também sobre etapas a cumprir e critérios para construir materiais pedagógicos.

Dou alguns exemplos sobre os quais trabalhei ou sobre os quais há trabalho conhecido. Sabemos hoje que a consciência silábica é um preditor de sucesso no desenvolvimento da leitura. Por isso, é preciso trabalhar atividades de manipulação da sílaba, fortemente inspiradas pelos estudos teóricos sobre desenvolvimento da fonologia, na educação pré-escolar.

Sabemos que a leitura passa muito por processos de antecipação de significados. Um trabalho sobre consciência morfológica, inspirado pelo conhecimento que a teoria nos dá sobre processos morfológicos produtivos, é crítico para a agilização de processos de leitura.

Os trabalhos da psicolinguística e da aquisição da linguagem mostram que há assimetrias na compreensão de dependências que envolvem movimento de sujeito ou de objeto direto. Isto permite dirigir atividades de estimulação, com seleção adequada de 
materiais, para os contextos que são de aquisição mais demorada. A consciência textual é crítica para que os alunos trabalhem textos de tipos e gêneros diferentes de forma adequada. Isto só é possível graças ao conhecimento bastante aprofundado que a linguística do texto nos dá sobre as características dos diferentes textos.

Estamos, portanto, perante contributos que não passam por um ensino de linguística formal ou teórica na escola, mas pela assunção clara de que sem linguística teórica a informar as práticas pedagógicas, estas são necessariamente mais pobres e até equivocadas.

Pires de Oliveira, Coelho e Monguilhott: Como o senhor avalia o trabalho que a escola vem desenvolvendo com gramática? O senhor acredita que houve mudança nos últimos anos?

João Costa: Obviamente que só posso comentar o caso português. Passamos de vários anos em que a gramática não foi ensinada para um momento de tomada de consciência sobre a necessidade de inscrever as competências gramaticais como nucleares e não subsidiárias no ensino da língua.

Há ainda trabalho a fazer. $\mathrm{O}$ ensino da gramática confunde-se, por vezes, com o ensino de uma nomenclatura, num quase processo de êxtase taxionômico. É necessário aprofundar as relações entre competências, a relevância do ensino da gramática e o seu uso como instrumento fundamental para o desenvolvimento de várias características que devem definir o cidadão do século XXI: a criatividade, a resolução de problemas, a capacidade de fazer perguntas e conduzir experimentação.

Pires de Oliveira, Coelho e Monguilhott: Sim! Esse é o ponto! Quais as experiências vivenciadas na escola com relação ao ensino de gramática que têm dado certo?

João Costa: Temos um corpo de evidência bastante robusto que mostra que o trabalho orientado para a promoção de consciência linguística é produtivo.

Pires de Oliveira, Coelho e Monguilhott: O senhor poderia citar algum trabalho nessa direção?

João Costa: Richard Hudson, Inês Duarte. ${ }^{1}$

\footnotetext{
${ }^{1}$ Richard Hudson tem publicado sobre linguística e em educação. Defende a ideia de que a linguística deve entrar na escola. http://dickhudson.com/papers/\#ed

Inês Duarte tem desenvolvido pesquisa em Linguística Educacional. http://www.clul.ulisboa.pt/en/ researchers-en/88-duarte-ines
} 
Pires de Oliveira, Coelho e Monguilhott: $\mathrm{O}$ senhor tem uma carreira acadêmica consolidada e tem trabalhado diretamente com questões de ensino de língua na escola. Poderia nos contar como tem sido essa sua atuação?

João Costa: Comecei por colaborar com o Ministério da Educação no Conselho Científico do Plano Nacional de Leitura. Integrei depois uma pequena equipa que preparou a versão final da Terminologia Linguística para o Ensino Básico e Secundário, na construção de um dicionário terminológico que atualizou e substituiu a Nomenclatura Gramatical Portuguesa. Coordenei a implementação do Programa de Português do Ensino Básico, em 2009, bem como o plano nacional de formação e acompanhamento das escolas. Desde então, passei a acompanhar com regularidade o trabalho de escolas e professores, acompanhando a sua formação inicial e contínua e participando em vários projetos relacionados com a qualidade do ensino.

Atualmente, integro o governo de Portugal, como Secretário de Estado da Educação.

Pires de Oliveira, Coelho e Monguilhott: Muito obrigada!

\section{Referências}

COSTA, J. Entrevista. eLingUp, v. 4, n. 1, 2012. [Centro de Linguística da Universidade do Porto].

COSTA, J.; Menuzzi, S.; WETZELS, L. (Ed.). Handbook of Portuguese Linguistics. 1. ed. Oxford: Wiley-Blackwell, 2016.

COSTA, J.; CASTRO, A.; LOBO, M.; PRATAS, F. (Ed.). Language Acquisition and Development. Proceedings of GALA 2009, 1. ed., Newcastle: Cambridge Scholars Publishing, 2010.

COSTA, J.; CABRAL, A. C.; SANTIAGO, A.; VIEGAS, F. Conhecimento Explícito da Língua. Guião de Implementação do Programa. 1. ed. Lisboa: Ministério da Educação Direção-Geral de Inovação e Desenvolvimento Curricular, 2010.

Perguntas enviadas em: 06/08/2017.

Resposta recebida em: 06/09/2017. 